\title{
Early Maladaptive Schemas, Depression Severity, and Risk Factors for Persistent Depressive Disorder: a Cross-sectional Study
}

\author{
KH Chen, WCC Tam, K Chang
}

\begin{abstract}
Objective: To investigate associations of the five early maladaptive schemas (EMS) domains with depression severity by comparing patients with persistent depressive disorder (PDD), patients with major depressive disorder (MDD), and controls with no psychiatric disorders.

Methods: Patients with PDD $(n=30)$, patients with MDD $(n=24)$, and controls with no psychiatric disorders $(n=30)$ were recruited. Participants were assessed using the Mini-International Neuropsychiatric Interview 5.0 version (MINI), the Beck Depression Inventory-Second Edition (BDI-II), and the Young Schema Questionnaire-3rd Edition Short Form (YSQ-S3).

Results: The five EMS domains (YSQ-S3 score) significantly correlated with depression severity (BDI-II score), with correlation coefficients ranging from 0.583 to 0.788 . After controlling for age, education, and sex, the two best predictors of depression severity were domains 'over-vigilance and inhibition' and 'disconnection and rejection'. For domains of disconnection and rejection, impaired autonomy and performance, and over-vigilance and inhibition, the total YSQ-S3 score was significantly higher in the PDD group than both the MDD and control groups. For the domain of impaired limits, the total YSQ-S3 score was significantly higher in both the PDD and MDD groups than the control group.

Conclusion: All five EMS domains correlated significantly with depression severity. PDD and MDD differed in psychopathology. The EMS domains of disconnection and rejection, impaired autonomy and performance, and over-vigilance and inhibition may be specific risk factors for PDD.
\end{abstract}

Key words: Depressive disorder; Risk factors

Kai-Hung Chen, MS, Department of Clinical Psychology, Ten Chen Hospital (Chungli), Taoyuan City, Taiwan

Wai-Cheong Carl Tam, PhD, Department of Psychology, Chung Yuan Christian University, Chungli, Taoyuan City, Taiwan

Kelly Chang, MD, Department of Psychiatry, Taipei Veterans General Hospital, Taoyuan Branch, Taoyuan City, Taiwan

Address for correspondence: Prof Wai-Cheong Carl Tam, Department of Psychology, Chung Yuan Christian University, 200 Chung Pei Rd., Chungli, Taoyuan City, Taiwan 32023.

Email: cheong@cycu.edu.tw

Submitted: 12 March 2018; Accepted: 10 December 2018

\section{Introduction}

Chronic depression is defined as having 2 years of continuous depressive symptoms. ${ }^{1,2}$ According to DSM-IV-TR, chronic depression diagnoses consist of dysthymic disorder, chronic major depressive episode, major depressive disorder with antecedent dysthymic disorder (double depression), major depressive episode in partial remission, and recurrent major depressive disorder without full inter-episode recovery. ${ }^{3}$ However, these diagnoses have few differences and can be viewed as a single broad condition. ${ }^{4-6}$ According to DSM-V, persistent depressive disorder (PDD) is used to include all these diagnoses of chronic depression. ${ }^{7}$
Early detection of high-risk patients is important in mental health services, as about $25 \%$ of depressed patients develop chronic depression in their lifetime ${ }^{8,9}$ Risk factors of chronic depression include younger age of onset, ${ }^{10}$ familial psychopathology, childhood adversity, depressive personality, rumination, chronic stress, low social support, and interpersonal difficulties. ${ }^{11,12}$ In a representative sample in the United States, predictors for chronic depression were female, having never married, having two or more chronic medical conditions, experiencing activity limitation, and less contact with family. ${ }^{13}$

There are various cognitive models of depression, including the cognitive triad, hopelessness theory, and rumination $^{14-16}$ as well as early maladaptive schema (EMS), which is defined as self-defeating, emotional and cognitive patterns that begin early in development and repeat throughout life. ${ }^{17}$ Early interaction with caregivers and traumatic experience contribute to the development of EMS. ${ }^{17-19}$ Accordingly, schema therapy is introduced for various mental disorders such as depression and personality disorders..$^{17,20}$

A total of 18 EMS were proposed and categorised in five domains: ${ }^{17}$

(1) Disconnection and rejection: it indicates that the expectation of a person's needs for security, safety, stability, nurturance, empathy, sharing of feelings, acceptance, and 
respect may not be met. This domain includes the schemas of abandonment/instability, mistrust/abuse, emotional deprivation, defectiveness/shame, and social isolation/ alienation.

(2) Impaired autonomy and performance: it involves expectations that a person possesses about oneself and the environment that interferes with his or her perceived ability to separate, survive, function independently or perform successfully. This domain includes the schemas of dependence/incompetence, vulnerability to harm or illness, enmeshment/undeveloped self, and failure.

(3) Impaired limits: it indicates the deficiency of a person in internal limits, responsibility to others, or longterm goal orientation. This domain includes the schemas of entitlement/grandiosity and insufficient self-control/selfdiscipline.

(4) Other-directedness: this is the excessive emphasis of a person on suppressing one's spontaneous feelings, impulses, and choices or on meeting rigid internalised rules and expectations about performance and ethical behaviour at the expense of happiness, self-expression, relaxation, close relationships, or health. This domain includes the schemas of negativity/pessimism, emotional inhibition, unrelenting standards/hypercriticalness, and punitiveness.

(5) Over-vigilance and inhibition: it involves a person's excessive focus on the desires, feelings, and responses of others, at the expense of one's own needs, in order to gain love and approval, maintain one's sense of connection, or avoid retaliation. This domain includes the schemas of subjugation, self-sacrifice, and approval-seeking/ recognition-seeking.

Depression severity is associated with EMS. ${ }^{18,19,21,22}$ The domains of disconnection and rejection, impaired autonomy and performance, and over-vigilance and inhibition are more elevated in patients with chronic depression than in patients with non-chronic depression. ${ }^{23}$ Schema therapy is a successful treatment for depression. ${ }^{17,24}$ Patients with bipolar disorder differ from patients with major depressive disorder (MDD) in terms of score in some EMS domains. ${ }^{25}$ However, more studies are needed to determine the cognitive risk factors for chronic depression..$^{10,12}$

The five EMS domains are categorised through robust psychometric methods and represent focused and comprehensive enduring cognitive patterns. ${ }^{17,23}$ This study aimed to investigate associations of the five EMS domains with depression severity by comparing patients with PDD, patients with MDD, and controls with no psychiatric disorders. We hypothesised that EMS domains are associated with depression severity, and that scores of EMS domains differ among the three groups.

\section{Methods}

This study was approved by institutional review board of Taipei Veterans General Hospital, Taoyuan Branch. The Declaration of Helsinki was followed. Informed consent was obtained from each participant. Patients with PDD
( $\mathrm{n}=30$ ), patients with MDD $(\mathrm{n}=24)$, and controls with no psychiatric disorders $(n=30)$ were recruited through advertisement. Those with depression were inpatients or outpatients of the hospital, whereas controls were nearby residents. Patients were excluded if they had a brain injury history, neurocognitive disorder (dementia), intellectual disability, bipolar and related disorders, or schizophrenia spectrum or other psychotic disorders. Only a few patients had comorbidity of substance-related disorders or anxiety disorders. All patients were on medication at the time of data collection. Participants were assessed using the MiniInternational Neuropsychiatric Interview 5.0 version (MINI) ${ }^{26}$ the Beck Depression Inventory-Second Edition (BDI-II), ${ }^{27}$ and the Young Schema Questionnaire-3rd Edition Short Form (YSQ-S3). ${ }^{28}$

The MINI was used to confirm the diagnosis of depression made by psychiatrists. It was established according to the DSM-IV and has the advantages of brevity, high sensitivity, high specificity, and ease of administration, and can be completed in about 15 to 20 minutes. To comply with DSM-V diagnostic criteria for PDD, the question of whether having depressive mood most of the time for the recent 2 years was changed to whether having depressive mood most of the time for at least 2 years in the past. In addition, having MDD did not rule out PDD.

The self-report BDI-II was used to assess depression severity and has good reliability and validity. It consists of 21 items; each item is rated on a 4-point scale ranging from 0 to 3 . The maximum total score is 63 ; higher scores indicate higher severity.

The YSQ-S3 was used to assess the 18 schemas in five domains of EMS. The third edition reveals more subtleties of each schema and provides more detailed information about the examinee, compared with previous versions. ${ }^{17}$ It has satisfactory reliability and validity for both the long and short forms ${ }^{17,29-33}$ and for different languages. ${ }^{32,34-39}$ The YSQ-S3 comprises 90 items; each is rated on a 6-point scale, ranging from 'completely untrue of me' to 'describes me perfectly'. The YSQ-S3 was translated into Chinese via rigorous forward and backward translation process.

Data were analysed using SPSS (version 20, IBM, Armonk [NY], US). Group characteristic differences were assessed using post-hoc comparisons (Games-Howell test). Associations of EMS domains with depression severity were assessed using Pearson correlations and stepwise regression. Scores of the EMS domains among the three groups were compared using the multivariate analysis of covariance and univariate analysis of covariance, with age and depression severity as control variables.

\section{Results}

Patients with PDD, patients with MDD, and controls with no psychiatric disorders were comparable except that patients with PDD and patients with MDD were older than controls, and that depression severity (BDI-II) and longest depressive episode was higher in patients with PDD than in 
patients with MDD (Table 1).

The internal consistency (Cronbach alpha) of the five EMS domain scores (disconnection and rejection, impaired autonomy and performance, impaired limits, other-directedness, and over-vigilance and inhibition) and total score was $0.943,0.919,0.804,0.821,0.910$, and 0.974 , respectively.

The five EMS domains (YSQ-S3 score) significantly correlated with depression severity (BDI-II score), with correlation coefficients ranging from 0.583 to 0.788 (Table 2).

Stepwise regression was conducted, with depression severity (BDI-II) as the dependent variable and EMS domains as predictors. As higher BDI-II score correlated with older age $(r=0.240, \mathrm{p}=0.028)$, lower education $(r=$ $-0.256, \mathrm{p}=0.019)$, and female sex $(r=0.250, \mathrm{p}=0.022)$, these variables were controlled. The two best predictors of depression severity were domains 'over-vigilance and inhibition' and 'disconnection and rejection' (Table 3).

The total YSQ-S3 scores (for EMS domains) of the three groups were compared using multivariate analysis of covariance. Age and BDI-II score were controlled as covariates. The Wilks' Lambda for EMS domains was 0.691 $(F=3.050, \mathrm{p}=0.002)$. Univariate analysis of covariance was conducted for each of the EMS domains, with age and BDI-II score as covariates. Bonferroni correction was used for post-hoc comparisons. For domains of disconnection and rejection, impaired autonomy and performance, and

Table 1. Clinical characteristics of participants.

\begin{tabular}{|lccccc|}
\hline Characteristic & $\begin{array}{c}\text { Persistent } \\
\text { depressive } \\
\text { disorder } \\
(\mathbf{n}=\mathbf{3 0})^{*}\end{array}$ & $\begin{array}{c}\text { Major } \\
\text { depressive } \\
\text { disorder } \\
(\mathbf{n = 2 4})^{*}\end{array}$ & $\begin{array}{c}\text { Control } \\
(\mathbf{n = 3 0})^{*}\end{array}$ & $\begin{array}{c}\text { Group } \\
\text { comparison }\end{array}$ & p Value \\
Age, y & $50.70 \pm 10.78$ & $51.54 \pm 12.78$ & $42.10 \pm 15.10$ & $\mathrm{~F}(2,81)=4.61$ & 0.013 \\
\hline Education, y & $10.57 \pm 4.72$ & $11.33 \pm 4.54$ & $12.60 \pm 4.40$ & $\mathrm{~F}(2,81)=1.52$ & 0.225 \\
\hline No. of males:females & $9: 21$ & $9: 15$ & $12: 18$ & $\chi^{2}(2)=0.70$ & 0.705 \\
\hline $\begin{array}{l}\text { Beck Depression } \\
\text { Inventory-2nd Edition }\end{array}$ & $38.97 \pm 10.94$ & $28.67 \pm 12.96$ & $2.97 \pm 2.81$ & $\mathrm{~F}(2,81)=109.54$ & $<0.001$ \\
\hline $\begin{array}{l}\text { Longest depressive } \\
\text { episode, mo }\end{array}$ & $137.40 \pm 108.39$ & $6.79 \pm 4.45$ & - & $\mathrm{t}(1,52)=6.59$ & $<0.001$ \\
\hline
\end{tabular}

* Data are presented as mean \pm standard deviation or No. of participants

Table 2. Correlations between depression severity and the five early maladaptive schema domains

\begin{tabular}{|c|c|c|c|c|c|c|}
\hline \multirow{2}{*}{$\begin{array}{l}\text { Early maladaptive } \\
\text { schema domain }\end{array}$} & \multirow{2}{*}{$\begin{array}{c}\text { Beck } \\
\text { Depression } \\
\text { Inventory- } \\
\text { 2nd Edition }\end{array}$} & \multicolumn{5}{|c|}{ Early maladaptive schema domain } \\
\hline & & $\begin{array}{l}\text { Disconnection } \\
\text { and rejection }\end{array}$ & $\begin{array}{c}\text { Impaired } \\
\text { autonomy } \\
\text { and } \\
\text { performance }\end{array}$ & $\begin{array}{c}\text { Impaired } \\
\text { limits }\end{array}$ & $\begin{array}{c}\text { Other- } \\
\text { directedness }\end{array}$ & $\begin{array}{c}\text { Over- } \\
\text { vigilance and } \\
\text { inhibition }\end{array}$ \\
\hline $\begin{array}{l}\text { Disconnection and } \\
\text { rejection }\end{array}$ & $\begin{array}{c}0.774 \\
(\mathrm{p}<0.001)\end{array}$ & & & & & \\
\hline $\begin{array}{l}\text { Impaired autonomy } \\
\text { and performance }\end{array}$ & $\begin{array}{c}0.690 \\
(\mathrm{p}<0.001)\end{array}$ & $\begin{array}{c}0.827 \\
(\mathrm{p}<0.001)\end{array}$ & & & & \\
\hline Impaired limits & $\begin{array}{c}0.587 \\
(\mathrm{p}<0.001) \\
\end{array}$ & $\begin{array}{c}0.724 \\
(\mathrm{p}<0.001) \\
\end{array}$ & $\begin{array}{c}0.629 \\
(\mathrm{p}<0.001) \\
\end{array}$ & & & \\
\hline Other-directedness & $\begin{array}{c}0.583 \\
(\mathrm{p}<0.001)\end{array}$ & $\begin{array}{c}0.720 \\
(\mathrm{p}<0.01)\end{array}$ & $\begin{array}{c}0.668 \\
(\mathrm{p}<0.001)\end{array}$ & $\begin{array}{c}0.650 \\
(\mathrm{p}<0.001)\end{array}$ & & \\
\hline $\begin{array}{l}\text { Over-vigilance and } \\
\text { inhibition }\end{array}$ & $\begin{array}{c}0.787 \\
(p<0.001)\end{array}$ & $\begin{array}{c}0.855 \\
(\mathrm{p}<0.001)\end{array}$ & $\begin{array}{c}0.750 \\
(\mathrm{p}<0.001)\end{array}$ & $\begin{array}{c}0.676 \\
(\mathrm{p}<0.001)\end{array}$ & $\begin{array}{c}0.797 \\
(\mathrm{p}<0.001)\end{array}$ & \\
\hline Overall & $\begin{array}{c}0.788 \\
(p<0.001)\end{array}$ & $\begin{array}{c}0.954 \\
(p<0.001)\end{array}$ & $\begin{array}{c}0.895 \\
(p<0.001)\end{array}$ & $\begin{array}{c}0.788 \\
(p<0.001)\end{array}$ & $\begin{array}{c}0.841 \\
(p<0.001)\end{array}$ & $\begin{array}{c}0.928 \\
(p<0.001)\end{array}$ \\
\hline
\end{tabular}


over-vigilance and inhibition, the total YSQ-S3 score was significantly higher in the PDD group than both the MDD and control groups. For the domain of impaired limits, the total YSQ-S3 score was significantly higher in both the PDD and MDD groups than the control group (Table 4).

\section{Discussion}

Our study confirmed that the EMS domains (YSQ-S3 score) correlated with depression severity and that YSQ-S3 score differed significantly among patients with PDD, patients with MDD, and controls with no psychiatric disorders. All five EMS domains correlated moderately to strongly with depression severity, consistent with previous studies that used the first version of the YSQ to assess EMS domains. ${ }^{18,19,21,22}$ In the third version, the number of EMS increased from 16 to 18 , and the domains 'undesirability' and 'restricted self expressed' were replaced with 'over-vigilance and inhibition', and the domain 'otherdirectedness' was added. In our study, the mean patient age was $>50$ years but it was $<40$ in previous studies. Stepwise regression analysis showed that the two best predictors of depression severity were domains 'over-vigilance and inhibition' and 'disconnection and rejection'. Clinicians should assess the EMS of patients to identify those who are prone to have more severe depression.

This study focused on the cognitive aspects of chronic depression. Depression was more severe in patients with PDD than in patients with MDD after controlling for age and depression severity, particularly in the domains of disconnection and rejection, impaired autonomy and performance, and over-vigilance and inhibition. This was consistent with results in a previous study ${ }^{23}$ that used the first version of the YSQ and a factor structure of four domains

Table 3. Stepwise regression analysis of depression severity with early maladaptive schema domains as predictors

\begin{tabular}{|llccccc|}
\hline Step & Predictor & $\mathbf{B}$ (standard error) & $\boldsymbol{\beta}$ & $\mathbf{t}(\mathbf{p}$ Value $)$ & \multicolumn{1}{|c|}{$\mathbf{R}^{\mathbf{2}}$} & $\mathbf{R}^{\mathbf{2}}$ \\
1 & Constant & $1.548(15.628)$ & & $0.099(\mathrm{p}=0.921)$ & 0.125 & 0.125 \\
\hline & Age & $0.258(0.164)$ & 0.191 & $1.571(\mathrm{p}=0.120)$ & & \\
\hline & Education & $-0.380(0.513)$ & -0.095 & $-0.742(\mathrm{p}=0.460)$ & & \\
\hline & Gender & $8.295(4.259)$ & 0.218 & $1.948(\mathrm{p}=0.055)$ & & 0.668 \\
\hline 2 & $\begin{array}{l}\text { Over-vigilance and } \\
\text { inhibition }\end{array}$ & $0.704(0.062)$ & 0.756 & $11.356(\mathrm{p}<0.001)$ & 0.543 & 0.699 \\
\hline 3 & $\begin{array}{l}\text { Disconnection and } \\
\text { rejection }\end{array}$ & $0.242(0.084)$ & 0.353 & $2.879(\mathrm{p}=0.005)$ & 0.032 & \\
\hline
\end{tabular}

Table 4. Univariate analysis of covariance for early maladaptive schema domains among participants.

\begin{tabular}{|c|c|c|c|c|c|c|c|}
\hline \multirow[t]{2}{*}{$\begin{array}{l}\text { Early } \\
\text { maladaptive } \\
\text { schema domains }\end{array}$} & \multicolumn{3}{|c|}{$\begin{array}{c}\text { Mean } \pm \text { SD domain score of Young } \\
\text { Schema Questionnaire-3rd Edition } \\
\text { Short Form }\end{array}$} & \multirow[t]{2}{*}{$\mathrm{SS}_{\text {group }} / \mathrm{SS}_{\text {error }}$} & \multirow[t]{2}{*}{$\underset{\text { df }_{\text {erroup }}}{\text { for }}$} & \multirow[t]{2}{*}{$\begin{array}{c}\mathbf{F} \\
(\mathbf{p} \text { Value) }\end{array}$} & \multirow[t]{2}{*}{$\begin{array}{l}\text { Post-hoc } \\
\text { comparison }\end{array}$} \\
\hline & $\begin{array}{l}\text { Persistent } \\
\text { depressive } \\
\text { disorder } \\
\text { (PDD) }\end{array}$ & $\begin{array}{l}\text { Major } \\
\text { depressive } \\
\text { disorder } \\
\text { (MDD) }\end{array}$ & Control & & & & \\
\hline $\begin{array}{l}\text { Disconnection and } \\
\text { rejection }\end{array}$ & $91.77 \pm 22.43$ & $62.96 \pm 12.92$ & $40.97 \pm 8.68$ & 6270.5 / 17301.4 & $2 / 79$ & $\begin{array}{c}14.32 \\
(\mathrm{p}<0.001) \\
\end{array}$ & $\begin{array}{c}\text { PDD }>\text { MDD, } \\
\text { control }\end{array}$ \\
\hline $\begin{array}{l}\text { Impaired autonomy } \\
\text { and performance }\end{array}$ & $66.60 \pm 20.66$ & $48.75 \pm 12.70$ & $32.47 \pm 6.64$ & $2365.5 / 15803.7$ & $2 / 79$ & $\begin{array}{c}5.91 \\
(\mathrm{p}=0.004)\end{array}$ & $\begin{array}{c}\text { PDD }>\text { MDD, } \\
\text { control }\end{array}$ \\
\hline Impaired limits & $34.90 \pm 8.18$ & $29.67 \pm 8.84$ & $21.60 \pm 5.88$ & $411.7 / 4135.7$ & $2 / 79$ & $\begin{array}{c}3.93 \\
(\mathrm{p}=0.024)\end{array}$ & $\begin{array}{l}\text { PDD, MDD > } \\
\text { control }\end{array}$ \\
\hline Other-directedness & $57.77 \pm 13.93$ & $50.13 \pm 7.66$ & $40.27 \pm 8.00$ & $502.7 / 8257.7$ & $2 / 79$ & $\begin{array}{c}2.41 \\
(\mathrm{p}=0.097)\end{array}$ & - \\
\hline $\begin{array}{l}\text { Over-vigilance and } \\
\text { inhibition }\end{array}$ & $83.00 \pm 16.62$ & $66.25 \pm 10.18$ & $46.73 \pm 8.74$ & $1752.5 / 10568.4$ & $2 / 79$ & $\begin{array}{c}6.55 \\
(\mathrm{p}=0.002)\end{array}$ & $\begin{array}{c}\text { PDD }>\text { MDD, } \\
\text { control }\end{array}$ \\
\hline
\end{tabular}


(without other-directedness domain) and included patients with DSM-IV dysthymic disorder. The present study used the YSQ-S3 and DSM-V diagnostic criteria for PDD. Compared with patients with MDD, those with PDD are more sensitive to social rejection, interpersonal instability, failure, vulnerability in self-functioning, subjugation, and approval-seeking. All these may in turn trigger more dysfunctional responses and maladaptive coping styles. According to the theory of development of EMS, patients with PDD may suffer more childhood adversity than those with MDD. ${ }^{11,17}$ Patients with PDD usually possess rigid internalised expectations and believe in their impairment in self-regulation. ${ }^{23}$ Thus, domains disconnection and rejection, impaired autonomy and performance, and overvigilance and inhibition may be specific cognitive risk factors for PDD. Nonetheless, further research with a large sample is needed to confirm this possibility.

There are several limitations to this study. Participants were recruited by purposive sampling and had potential bias. The sample was small and consisted of depressed patients aged 40 to 60 with high school to college education. Some patients with PDD or MDD had comorbidity of substance-related disorders or anxiety disorders and may have resulted in confounding effects. Other possible confounding variables such as family history of depression, medical illness, and social support were not examined. The cross-sectional design cannot determine causality. The selfreported instruments rely on the memory of the participants which might be inaccurate. ${ }^{40}$

\section{Conclusion}

All five EMS domains correlated significantly with depression severity. PDD and MDD differed in psychopathology. The EMS domains of disconnection and rejection, impaired autonomy and performance, and overvigilance and inhibition may be specific risk factors for PDD.

\section{Acknowledgements}

The authors would like to thank psychiatrists Hae-Lanq Wei and Li-Ren Shu and clinical psychologist Huei-Ching Tsai for their help in data collection.

\section{Declaration}

All authors have no conflicts of interest to disclose.

\section{References}

1. Rhebergen D, Beekman AT, de Graff R, Nolen WA, Spijker J, Hoogendijk WJ, et al. The three-year naturalistic course of major depressive disorder, dysthymic disorder and double depression. J Affect Disord 2009;115:450-9. Crossref

2. Torpey DC, Klein DN. Chronic depression: update on classification and treatment. Curr Psychiatry Rep 2008;10:458-64. Crossref

3. American Psychiatric Association. Diagnostic and Statistical Manual of Mental Disorders. 4th edition, text revision. Washington, DC: American Psychiatric Association; 2000.

4. Klein DN, Shankman SA, Rose S. Ten-year prospective follow-up study of the naturalistic course of dysthymic disorder and double depression. Am J Psychiatry 2006;163:872-80. Crossref

5. McCullough JP Jr, Klein DN, Borian FE, Howland RH, Riso LP, Keller MB, et al. Group comparisons of DSM-IV subtypes of chronic depression: validity of the distinctions, part 2. J Abnorm Psychol 2003;112:614-22. Crossref

6. McCullough JP Jr, Klein DN, Keller MB, Holzer CE 3rd, Davis SM, Kornstein SG, et al. Comparison of DSM-III-R chronic major depression and major depression superimposed on dysthymia (double depression): validity of the distinction. J Abnorm Psychol 2000;109:419-27. Crossref

7. American Psychiatric Association. Diagnostic and Statistical Manual of Mental Disorders. 5th edition. Washington, DC: American Psychiatric Association; 2013. Crossref

8. Rubio JM, Markowitz JC, Alegría A, Perez-Fuentes G, Liu SM, Lin $\mathrm{KH}$, et al. Epidemiology of chronic and nonchronic major depressive disorder: results from the national epidemiologic survey on alcohol and related conditions. Depress Anxiety 2011;28:622-31. Crossref

9. Satyanarayana S, Enns MW, Cox BJ, Sareen J. Prevalence and correlates of chronic depression in the Canadian community health survey: mental health and well-being. Can J Psychiatry 2009;54:38998. Crossref

10. Hölzel L, Härter M, Reese C, Kriston L. Risk factors for chronic depression: a systematic review. J Affect Disord 2011;129:1-13. Crossref

11. Klein DN, Santiago NJ. Dysthymia and chronic depression: introduction, classification, risk factors, and course. J Clin Psychol 2003;59:807-16. Crossref

12. Riso LP, Miyatake RK, Thase ME. The search for determinants of chronic depression: a review of six factors. J Affect Disord 2002;70:103-15. Crossref

13. Walker ER, Druss BG. Rate and predictors of persistent major depressive disorder in a nationally representative sample. Community Ment Health J 2015;51:701-7. Crossref

14. Beck AT, Rush AJ, Shaw BF, Emery G. Cognitive Therapy of Depression. New York: Guilford Press; 1979.

15. Abramson LY, Metalsky GI, Alloy LB. Hopelessness depression: a theory-based subtype of depression. Psychol Rev 1989;96:35872. Crossref

16. Nolen-Hoeksema S. Responses to depression and their effects on the duration of depressive episodes. J Abnorm Psychol 1991;100:56982. Crossref

17. Young JE, Klosko JS, Weishar ME. Schema Therapy: a Practitioner's Guide. New York: Guilford Press; 2003.

18. Harris AE, Curtin L. Parental perceptions, early maladaptive schemas, and depressive symptoms in young adults. Cogn Ther Res 2002;26:405-16. Crossref

19. Wesley MS, Manjula M. Early maladaptive schemas and early trauma experiences in depressed and non-depressed individuals: an Indian study. J Psychosocial Res 2015;10:125-37.

20. Young JE. Cognitive Therapy for Personality Disorders: a Schemafocused Approach. Sarasota, FL: Professional Resource Exchange; 1990.

21. Halvorsen M, Wang CE, Richter J, Myrland I, Pedersen SK, Eisemann $\mathrm{M}$, et al. Early maladaptive schemas, temperament and character traits in clinically depressed and previously depressed subjects. Clin Psychol Psychother 2009;16:394-407. Crossref

22. Halvorsen M, Wang CE, Eisemann M, Waterloo K. Dysfunctional attitudes and early maladaptive schemas as predictors of depression: a 9-year follow-up study. Cogn Ther Res 2010;34:368-79. Crossref

23. Riso LP, du Toit PL, Blandino JA, Penna S, Dacey S, Duin JS, et al. Cognitive aspects of chronic depression. J Abnorm Psychol 2003;112:72-80. Crossref

24. Hawke LD, Provencher MD. Schema theory and schema therapy in mood and anxiety disorders: a review. J Cognit Psychother 2011;25:257-76. Crossref 
25. Nilsson KK, Nielsen Straarup K, Halvorsen M. Early maladaptive schemas: a comparison between bipolar disorder and major depressive disorder. Clin Psychol Psychother 2015;22:387-91. Crossref

26. Sheehan DV, Lecrubier Y, Sheehan KH, Amorim P, Janavs J, Weiller E, et al. The Mini-International Neuropsychiatric Interview (M.I.N.I.): the development and validation of a structured diagnostic psychiatric interview for DSM-IV and ICD-10. J Clin Psychiatry 1998;59(Suppl 20):22-33.

27. Chen HY. Manual for the Chinese Edition Beck Depression InventoryII [in Chinese]. Taipei, Taiwan: Chinese Behavior Science Corporation; 2000.

28. Young YE. Young Schema Questionnaire-Short Form 3 (YSQ-S3). New York: Schema Therapy Institute; 2005. Crossref

29. Schmidt NB, Joiner TE, Young JE, Telch MJ. The Schema Questionnaire: investigation of psychometric properties and the hierarchical structure of a measure of maladaptive schemas. Cogn Ther Res 1995;19:295-321. Crossref

30. Lee CW, Taylor G, Dunn J. Factor structure of the Schema Questionnaire in a large clinical sample. Cogn Ther Res 1999;23:44151. Crossref

31. Hoffart A, Sexton H, Hedley LM. The structure of maladaptive schemas: a confirmatory factor analysis and a psychometric evaluation of factor-derived scales. Cogn Ther Res 2005;29:627-44. Crossref

32. Baranoff J, Oei TP, Cho SH, Kwon SM. Factor structure and internal consistency of the Young Schema Questionnaire (Short Form) in Korean and Australian samples. J Affect Disord 2006;93:133-
40. Crossref

33. Samuel DB, Ball SA. The factor structure and concurrent validity of the Early Maladaptive Schema Questionnaire: Research version. Cogn Ther Res 2013;37:150-9. Crossref

34. Calvete E, Orue I, Gonzalez-Diez Z. An examination of the structure and stability of early maladaptive schemas by means of the Young Schema Questionnaire-3. Eur J Psychol Assess 2013;29:28390. Crossref

35. Cui L, Lin W, Oei TPS. Factor structure and psychometric properties of the Young Schema Questionnaire (Short Form) in Chinese undergraduate students. Int J Mental Health Addict 2011;9:64555. Crossref

36. Saritas D, Gencoz T. Psychometric properties of "Young Schema Questionnaire-Short Form 3" in a Turkish adolescent sample. J Cogn Behav Psychother 2011;11:83-96.

37. Kriston L, Schafer J, Jacob GA, Harter M, Hölzel LP. Reliability and validity of the German version of the Young Schema QuestionnaireShort Form 3 (YSQ-S3). Eur J Psychol Assess 2013;29:205-12. Crossref

38. Trip S. The Romanian version of Young Schema Questionnaire-Short Form 3 (YSQ-S3). J Cogn Behav Psychother 2006;6:173-81.

39. Lee SJ, Choi YH, Rim HD, Won SH, Lee DW. Reliability and validity of the Korean Young Schema Questionnaire-Short Form-3 in medical students. Psychiatry Investig 2015;12:295-304. Crossref

40. Hardt J, Rutter M. Validity of adult retrospective reports of adverse childhood experiences: review of the evidence. J Child Psychol Psychiatry 2004;45:260-73. Crossref 